\title{
The Effect of Push-Up Exercise with Wrist Flicking on the Ability of Three Point Shooting of BSWJ Club Basketball Players
}

\author{
Ahmad Maulana, Herita Warni, Syamsul Arifin \\ Master Program of Sport Education \\ Faculty of Teacher Training and Education \\ Lambung Mangkurat University \\ Banjarbaru, Indonesia
}

\begin{abstract}
This study aimed to determine the effect of pushup exercise with wrist flicking on the ability of basketball three point shooting in BSWJ Club Age 16 - 18 Years. The method used was pre-experimental design. The population in this study was all 20 players of BSWJ basketball Club Age 16-18 years. All players became the sample since it occupied total sampling technique. The results showed that the data of pretest shooting three point of BSWJ Club gained an average 3.35 with standard deviation $=1.899$. On post test data of shooting threepoint basketball of BSWJ Club, it gained average $=6.50$ with standard deviation $=2.482$. Correlation result is 0.921 with significant $0.000<0.05$. Thus, there is a significant difference between the pretest and posttest. The conclusion is that there is the effect of push-up exercies with wrist flicking on the ability of basketball three point shooting in BSWJ Club age 16 - 18 years.
\end{abstract}

Keywords: effect, push-up exercise, three point shooting, basketball

\section{INTRODUCTION}

To achieve high achievement, we must always pay attention to the limits of the ability of each individual or athlete. The ability of each athlete is surely different and is influenced by the genetic capability that includes strength, velocity (speed) and durability (endurance). This is as explained by reference [1], "The ability to perform certain exercises varies from athlete to athlete, and an athlete's ability to perform at a high level is influenced by inherited (or genetic) abilities in strength, speed, and endurance." Thus, with the knowledge of one's ability limit, we will be able to determine precisely both the workload of training and predicting achievements that can be scientifically justified.

In addition to the athlete's genetic potential, the athlete's success in achievement is also determined by the training program he runs. Therefore, a coach must create an exercise program that is effective. The effective exercise program lies in the selection of enough exercise. The amount and type of exercise must be chosen based on the age and level of the athlete's performance, sporting needs, and training phase. To obtain the desired performance, every athlete always tries to prepare himself with physical condition, mastery of techniques, tactics and mental. These four ability factors can be improved through relatively long practice and good training programs.
In basketball sport, shooting is the most popular basketball basic skill because every player must have the instinct to score. Shooting is the final goal of every player where the success of a team in the game is always determined by the success in putting the ball into the basket. The observations of the researcher in the field as the basketball coach of Banjarbaru Spartan Warrior Junior (BSWJ) team showed that the basketball players of the BSWJ club have good shooting techniques because they are trained in technical skills specifically by specialized technical trainers. The players have been able to do the shooting movement properly. However, there are basketball players who have not attained the good shooting ability. When shooting, the result of the ball entering the ring is still low, especially when doing three-point shooting. Most of their three-point shots did not even reach the ring. Whereas three-point shooting is very important skill as stated by reference [2] that three-point shot is one of the weapons to win the match and turns things around when our team loses.

Based on the observations and analysis of the researcher in the field, to be able to do three-point shooting accurately players must have strong arm muscles and high wrist flexibility. This is because with a strong-arm muscle, the player can push the ball until it reaches the ring and with the flexibility of wrist, the player can control the direction of the ball so that the ball enters the ring.

Based on this background, the writer feels interested in researching the effect of push-up exercises on the ability of three-point shooting because it is practical and can be modified according to the needs of the exercise. Push-up exercise is popular because it is easy to learn, does not require any equipment, can be adapted to different fitness levels, and can be modified as needed exercise. Pushup exercises can be modified by changing the position of the hands and feet or by adding movement. Push-up exercise is modified to increase muscle strength and wrist flexibility of basketball athletes. In addition, modified push up exercises can also be a variation of the exercise, so it is not monotonous.

Push-up exercise modification in this study is the push-up exercise with wrist flicking. The push-up with wrist flicking exercise is useful exercise for increasing arm muscle strength and the flexibility of the wrist of a basketball athlete. Therefore, training to improve arm 
- Passive stretching. The implementation is that the athlete tries to keep certain groups of muscles relaxed. Next, his friend helps to stretch the muscle slowly until the pain point is reached. The stretch is maintained for 20-30 seconds.

\section{LITERATURE REVIEW}

\section{A. Strength Training}

Strength, especially arm muscle strength, is an element of physical condition that is needed in basketball because basketball requires players to perform arm movements such as dribbling, passing, and shooting. Without excellent strength, players will have difficulty doing various basketball sports techniques. Strength training can be done using one's own body weight or outside loads. Reference [3] recommends that young athletes do a variety of weight training using their own body weights such as push-ups, situps, step-ups, and skipping. Hence, strength is one of the basic components of biomotor needed in every sport, including basketball. By having excellent strength, a basketball player can throw, jump, and shoot further and efficiently.

Strength training can be done using one's own body weight or outside loads, reference [3] recommends that young athletes do a variety of weight training using their own body weights. In this study the burden used is our own limbs by doing push-up with wrist flicking with the consideration that it is more practical and safer to do.

\section{B. Flexibility Training}

Basketball is a sport that requires high wrist flexibility because the player must perform a variety of hand movements such as passing, dribbling and shooting. According to reference [4], Flexibility is the ability to move joints in full range of movement and free from discomfort and pain. The similar opinion proposed by reference [5] that flexibility is the ability to move a right body and the body parts in a space that is as broad as possible, without suffering, causing injury to the joints and the muscles around the joints. Therefore, flexibility is the ability to move the body, joints, or muscles as comfortable as possible without injury.

The role of wrist flexibility in basketball can be seen in shooting skill. This is as stated by reference [2] that the final step in good shooting is the movement of the hands by following towards the ring. Keeping the elbows locked and using the final push power of the wrist.

Flexibility is really needed by every athlete so that they are easy to learn various movements, improve skills, reduce the risk of injury, and optimize strength, speed, and coordination. Reference [4] explains that the features of flexibility exercises are: (1) stretching the joints, (2) stretching out a group of muscles. Flexibility can be developed through stretching exercises. The model consists of:

- Stretching dynamic (Dynamic stretch), which is also called ballistic stretching is stretching done by moving the body or limbs rhythmically.

- Static stretching is a way to stretch a group of muscles slowly to the point of pain which is then maintained for 20 to 30 seconds. Done in several times, for example 3 times for each form of exercise.
- Proprioceptive Neuromuscular Facilitation (PNF). Athlete is holding out with the help of other, athlete who is doing static stretches. Furthermore, his friend pushes slowly and athlete who is stretching holds it until the contraction's isometric happens. Few seconds later, the athlete doing stretching does his relaxation and his friend keeps pushing until the optimum point.

\section{1) Exercise Method}

To increase the strength of an athlete, the trainer needs to determine the right strength training method. Reference [1] states that strength training aims to increase the maximum strength (maximum strength), power, and muscle endurance (muscular endurance). The strength that became the focus of this research is the maximum strength. Reference [1] defines maximum strength as the greatest effort that can be carried out by the neuromuscular system in one contraction.

Reference [6] states that in order to increase the maximum strength, there are two methods of exercise that are commonly used:

- The Hypertrophy method is used to increase the diameter of the muscle to be greater so that the strength of the muscle increases. In this method the intensity of the exercise is between 30-60\%; the contraction is slow with a lot of reps.

- The Neural Activation Method is used to improve intramuscular coordination. In this method, the exercise can be given in zones of intensity of 30-60\%, $60-70 \%, \quad 70-80 \%, \quad 80-85 \%, \quad 85-90 \%$, and 90$100 \%$ with the rate of rapid contraction and slight repetition.

In this study, strength training method used is method of Neural Activation is the intensity of $30-60 \%$, with the rhythm of rapid contraction and little repetition. Because in shooting, the most important thing is not the size of the player's arm muscles but strong muscles with good intramuscular coordination so that they can do accurate shooting.

\section{Push-up Exercises with Wrist Flicking}

Push-up training is a strength training method to increase shoulder strength and arm muscles [3]. Push-up can also be called the movement of pushing the body up when facedown with both hands beside the chest and done repeatedly. Pushups are very popular to be used in exercise programs to increase upper body strength, including arm muscle strength. Reference [7] state that pushups are popular exercises because they are easy to learn, do not require any equipment, can be adapted to various levels of fitness, and can be modified according to training needs. Pushup exercises can be modified by changing the position of the hands and feet or by adding movement.

Modified push-up exercises in this study are pushup exercises with wrist flicking. Push-up exercises with wrist flicking are useful exercises for increasing arm muscle 
- When the arms are straightened, the palms are pushed

strength and the flexibility of the wrist of a basketball athlete. Reference [8] explained that the exercise by the the wrist flicking is an effective activity to increase the shot strength of the wrist. Additionally, reference [3] describes pushup exercises as a method of strength training to increase shoulder strength and arm muscles.

Arm muscle strength and wrist flexibility are very important roles to excel in basketball so that players get a good percentage in shooting [2]. Therefore, training to improve arm muscle strength and wrist flexibility of athletes must receive great attention in order to improve the athlete's shooting ability.

\section{Shooting}

Reference [9] issued by the International Basketball Federation states, "A shoot is when the ball is held in the player's hand(s) and then into the air towards the opponents' basket." This means that a shot is when the ball is held in the hands of the player and then thrown into the air into the opponent's basket. Thus, shooting is an ability that every basketball player must possess in order to score.

In order to get good results in shooting, players must be trained to shoot at several points. According to reference [2] for novice players, they do shooting practice at points which is close to the ring. When the percentage is good enough, it moves to a point with a longer distance until they reach the 3-point shot point.

\section{METHOD}

The method used in this study was preexperimental design. The pre-experimental design used was the One Group Pretest-Posttest design, which means that a group of subjects is subject to treatment for a certain period of time, while measurements are taken before and after the treatment is given and the treatment effect is measured by the difference between the initial measurement $(\mathrm{O} 1)$ and the measurement end $(\mathrm{O} 2)[10]$, with the following schematic:

O 1 $\mathrm{X}$ O 2

Image Caption:

O1: Pretest of shooting ability

$\mathrm{X}$ : The series of Push-up Exercise with wrist flicking

O2: Posttest of shooting ability

The population in this study was all the 20 players in the BSWJ club and the entire of the population became sample. Basketball player Club BSWJ consisted of 20 people performer men aged 16 to 18 years. The data collection of players' three-point shooting ability was done with the instrument test of three-point shooting.

\section{A. Exercise Series (Treatment)}

The treatment of push-up with wrist flicking was given in two months, three times a week. The goal: Strengthen the arm muscles and flex the wrist. How to do it:

- At first, sleep on the stomach, legs pressed together behind, feet rested on the floor

- Both palms beside the chest, fingers pointing forward and elbows bent

- Then, lift the body up until both hands are straight and body and legs are a straight line from the base of the arms to the tips of the fingers and then whipped.

TABLE I. THE EXERCISE PROGRAM OF PUSH-UP WITH WRIST FLICKING

\begin{tabular}{|l|l|l|l|l|l|l|l|l|l|}
\hline \multirow{2}{*}{ Week } & \multicolumn{3}{|c|}{ Monday } & \multicolumn{3}{c|}{ Wednesday } & \multicolumn{3}{|c|}{ Friday } \\
\cline { 2 - 11 } & Set & rep & Dose & Set & Rep & Dose & Set & rep & Dose \\
\hline 1 & 2 & IT & $30 \%$ & 3 & IT & $30 \%$ & 4 & IT & $30 \%$ \\
\hline 2 & 2 & IT & $40 \%$ & 3 & IT & $40 \%$ & 4 & IT & $40 \%$ \\
\hline 3 & 2 & IT & $50 \%$ & 3 & IT & $50 \%$ & 4 & IT & $45 \%$ \\
\hline 4 & 2 & IT & $60 \%$ & 3 & IT & $60 \%$ & 4 & IT & $60 \%$ \\
\hline 5 & 2 & IT & $50 \%$ & 3 & IT & $45 \%$ & 4 & IT & $35 \%$ \\
\hline 6 & 2 & IT & $30 \%$ & & & & & & \\
\hline
\end{tabular}

Note: IT = Everyone (Max Test results at times the dose)

Data Analysis Design:

- Normality Test with Kolmogorov Smirnov (SPSS20).

- Homogeneity Test with Test of Homogeneity of Variance (SPSS20).

- Hypothesis testing with Paired Samples TTest (SPSS20).

\section{RESUlTS AND DISCUSSION}

Descriptive statistical analysis of the preliminary test and the final test results of the shooting of three-point basketball players of the Banjarbaru BSWJ Club are presented in the following table.

TABLE II. DESCRIPTIVE STATISTICAL ANALYSIS OF PRETEST AND POST TEST RESULTS OF THREE-POINT SHOOTING

\begin{tabular}{|l|l|l|l|l|l|}
\hline & N & Minimum & Maximum & Mean & $\begin{array}{c}\text { Std. } \\
\text { Deviation }\end{array}$ \\
\hline $\begin{array}{l}\text { Pre-Test of Three } \\
\text { Point Shooting }\end{array}$ & 1 & 7 & 3.35 & 1,899 \\
\hline $\begin{array}{l}\text { Post Test of Three } \\
\text { Point Shooting }\end{array}$ & 20 & 3 & 13 & 6.50 & 2,482 \\
\hline
\end{tabular}

The normality test is done with the Kolmogorov-Smirnov Test and Test of Homogeneity of Variance using the SPSS 20 Program.

TABLE III. NORMAL TEST WITH THE KOLMOGOROV-SMIRNOV ONESAMPLE TEST ON PRETEST RESULTS AND POST TEST RESULTS OF SHOOTING THREE POINT

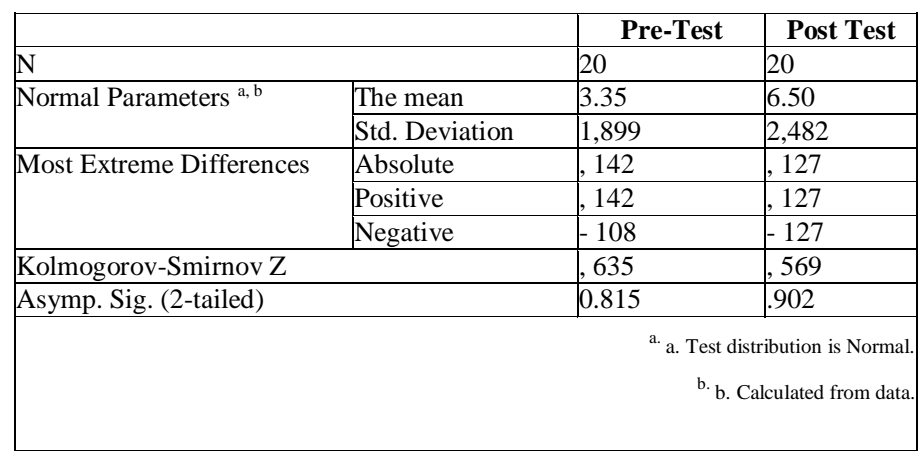

Based on the normality of data on Asymp. Sig. (2tailed) above, it is found that pretest shooting three-point ball basketball $(\mathrm{O} 1)(0.815>0.05)$. Posttest of shooting threepoint ball basketball $(\mathrm{O} 2)(0.902>0.05)$ 


\section{A. Hypothesis Testing}

Research Hypothesis Test with Paired Samples TTest is the Twice Measurement Difference Test which is classified as parametric statistics or for normally distributed data and homogeneous samples.

TABLE V. PAIRED SAMPLES STATISTICS

\begin{tabular}{|l|l|l|l|l|l|}
\hline \multicolumn{2}{|c|}{} & The mean & N & $\begin{array}{c}\text { Std. } \\
\text { Deviation }\end{array}$ & $\begin{array}{c}\text { Std. } \\
\text { Error Mean }\end{array}$ \\
\hline \multirow{2}{*}{ Pair 1} & Pre-Test & 3.35 & 20 & 1,899 &, 425 \\
\cline { 2 - 6 } & Post Test & 6.50 & 20 & 2,482 &, 555 \\
\hline
\end{tabular}

TABLE VI. PAIRED SAMPLES CORRELATIONS

\begin{tabular}{|l|l|l|l|l|}
\hline \multicolumn{2}{|l|}{} & \multicolumn{1}{|c|}{$\mathbf{N}$} & \multicolumn{1}{|c|}{ Correlation } & \multicolumn{1}{c|}{ Sig. } \\
\hline Pair 1 & $\begin{array}{l}\text { Pre-Test and } \\
\text { Post Test }\end{array}$ & 20 & 0.921 & 0,000 \\
\hline
\end{tabular}

Table 6 shows the correlation between data of pretest and posttest of three-point shooting. There is a correlation of 0,921 with a significance of $0.000<0.05$. This states that the correlation between before and after being treated with push-up exercises with wrist flicking is very closely and truly correlated.

Based on Table above the Siq value based on Mean of $0.284>0.05$, it can be concluded that data of pretest and posttest is homogeneous.

TABLE VII. PAIRED SAMPLES T-TEST

\begin{tabular}{|c|c|c|c|c|c|c|c|c|c|}
\hline & \multicolumn{5}{|c|}{ Paired Differences } & \multirow{3}{*}{$\mathbf{T}$} & \multirow{3}{*}{ Df } & \multirow{3}{*}{ Sig. (2-tailed) } \\
\hline & & \multirow{2}{*}{ The mean } & \multirow{2}{*}{$\begin{array}{l}\text { Std. } \\
\text { Deviation }\end{array}$} & \multirow{2}{*}{ Std. Error Mean } & \multicolumn{2}{|c|}{$\begin{array}{l}95 \% \text { Confidence Interval of } \\
\text { the Difference }\end{array}$} & & & \\
\hline & & & & & Lower & Upper & & & \\
\hline \begin{tabular}{|l} 
Pair 1 \\
Pre-Test \\
Post Test
\end{tabular} & and & $-3,15$ & 1.04 & 0,233 & -3.64 & -2.66 & 13.5 & 19 & 0,000 \\
\hline
\end{tabular}

Through difference test of Paired Samples T-Test, it is
ined that there is a significant difference from the result of shooting three point on Basketball players of BSWJ before and after treatment of push-up exercise with wrist flicking for 6 weeks, with a significance of $0.000<0.05$. It means there is a significant difference in the measurement of the pretest data and post test data of three-point shooting basketball test. The post three point basketball shooting test data with an average of 6.50 has an average that is greater than the pre-three-point basketball shooting test data of $=3.35$. It means the results of the hypothesis testing of push-up exercises with wrist flicking are proven to provide an increase in the ability of threepoint shooting of BSWJ Basketball Players.

The pretest results of three-point shooting on basketball players BSWJ got the average of 3:35 and the standard deviation amounted to 1,899 . The test obtained highest score (7) and lowest score (1). After being treated with arm muscle strength training and wrist flexibility through push-up exercises with wrist flicking, there was a significant increase in basketball three-point shooting results. This is proven by the results of the posttest of three-point shooting which
Based on the observations of researcher in the field and the results of the pretest, the results of shooting threepoint BSWJ players are still not optimal. In the pretest, players were asked to do three-point shooting at three points, and they were given 30 seconds at each point. It turned out that their three-point shooting results were not accurate, even many were not about the ring. Based on the observations of the researcher, this was caused by weak arm muscle strength and low wrist flexibility. Therefore, the researcher gave the arm muscle strength training and wrist flexibility exercises, namely push-up exercises with wrist flicking.

In this study, the researcher provided treatments to improve arm muscle strength and wrist flexibility in the form of pushups that were modified according to the principles of exercise. The training load given to BSWJ players is 30 to $60 \% 1 \mathrm{RM}$. This is in accordance with the theory put forward by reference [1] which states that in training that is focused on increasing strength, an athlete must use a load of around 30 to $60 \% 1 \mathrm{RM}$. 
exercise program must be based on the theory and principles of training so that the training objectives can be achieved.

\section{CONCLUSION}

The conclusion of this study is based on data analysis, hypothesis testing and the discussion that has been done in the previous chapter that there is a positive and significant effect of $0,000<0.05$ push-up training with wrist flicking on the three-point shooting ability of BSWJ club basketball. Based on the conclusions that have been stated, the researcher proposes the following suggestions:

- The managers of PERBASI Banjarbaru and the Coach of BSWJ can continue to carry out the push-up exercise with wrist flicking into the exercise program in efforts to improve basketball three-point shooting ability of the players.

- For the basketball players of BSWJ as subjects who are directly involved in the research, practicing the push-up with wrist flicking should be continued in order to improve the accuracy of their three-point shooting.

\section{REFERENCES}

[1] T. Bompa, and B. Carlo, Periodisation Training for Sports. New York: Human Kinetics, 2015.

[2] D. Kosasih, Fundamental Basketball First Step To Win. Semarang: Karangturi Media. 2008.

[3] S. Froling, Australian Basketball Star Drills and Skills. Surabaya: Honda DBL Camp, 2016.

[4] G. Brittenham, Bola Basket Panduan Lengkap Latihan Khusus Pemantapan. Jakarta: Rajagrafindo Persada, 1998.

[5] N. Nurhasan and H. Kholil, Modul Tes dan Pengukuran Keolahragaan. Bandung: Universitas Pendidikan Indonesia, 2007.

[6] J. Lin, and C. Tinghao, Diversity of Strength Training Method: A Theoretical Approach. Strength and Conditioning Journal. Taiwan: NSCA, 2012

[7] M. K. Gouvali, and B. Konstantinos, Dynamic and Electromyographical Analysis in Variants of Push-up Exercise. Journal of Strength and Conditioning Research. Athens: National Strength \& Conditioning Association, 2004.

[8] J. Oliver, Dasar-Dasar Bola Basket. Bandung: Pakar Raya, 2009.

[9] Official Basketball Rules 2012 as Approved bay FIBA Central Board Rio de Jeneiro, Brazil, 29 ${ }^{\text {th }}$ April 2012

[10] S. Sugiyono, Metode Penelitian Kombinasi (Mixed Methods). Bandung: Alfabeta, 2014.

[11] D. A. Chu, and G. C. Myer, Plyometrics. USA: Human Kinetics, 2013. reference [11] that in resistance training that is focused on increasing strength, an athlete must use a load of around 30 up to $60 \% 1 \mathrm{RM}$. Therefore, every trainer in compiling an 